RU Продуктивные способы образования неологизмов концептуализированной группы Brexit в современном англоязычном массмедийном дискурсе

\author{
Васьбиева Д. Г.
}

Аннотация. Цель исследования - выявление наиболее продуктивных моделей образования неологизмов в массмедийном дискурсе на основе анализа новой лексики концептуализированного гнезда Brexit. Научная новизна исследования выражена в обращении к неологизмам английского языка с компонентом Brexit как стратегической единице коммуникации, повышающей значимость современного массмедийного дискурса, и заключается в том, что в нем представлен ряд частных наблюдений и выводов, сделанных в результате анализа конкретного материала. В результате установлено, что наиболее продуктивными способами образования неологизмов словообразовательной модели Brexit являются словосложение, аффиксация и сокращение.

\title{
EN Productive Ways to Form Neologisms of the Conceptualized Group "Brexit" in the Modern English-Language Media Discourse
}

\author{
Vasbieva D. G.
}

\begin{abstract}
The paper aims to identify the most productive models of neologism formation in the Englishlanguage media discourse. The research material includes neologisms of the conceptual-thematic area Brexit. Scientific originality of the study is conditioned by the fact that the English neologisms with the component Brexit are considered as an essential element of communication and an integral part of modern media discourse. The author presents observations and conclusions based on an analysis of factual material. The findings of this study indicate that the most productive ways of the Brexit neologism formation are stem composition, affixation and shortening.
\end{abstract}

\section{Введение}

Научно-технический прогресс, начавшийся во второй половине XX века, служит сильным стимулом для обогащения и расширения лексики языковой картины мира. Однако не только развитие современных технологий способствует обновлению и дополнению английского словаря новыми словами, но и появление новых социальных явлений, политических ситуаций и изменение стиля жизни. Новые слова, возникающие как результат прямого отражения вышеупомянутых явлений, процессов и научно-технических открытий в языке (например, «ликомбез» - ликвидация компьютерной безграмотности, копирайтер (от англ. copywriting) - специалист по написанию текстов для презентаций и рекламы), называются неологизмами. По мнению И. В. Арнольд, «неологизмы - новые слова или словосочетания, а также новые значения, появившиеся у существующих слов, или даже слова, заимствованные из других языков» [1, с. 157].

Актуальность исследования обусловлена особым интересом современной лингвистики к изучению языкового материала, позволяющему определить, как новая терминология дискурса СМИ становится частью когнитивной картины мира в ее связи с языковой картиной мира. Необходимость популяризации знаний данной терминологии продиктована сменой технико-экономической парадигмы и происходящими событиями в экономико-политической жизни страны. Кроме того, в эпоху глобализации всех сфер жизнедеятельности общества все еще сохраняются вызовы в сфере повышения уровня взаимопонимания и сотрудничества между представителями различных международных организаций, сфер бизнеса и экономических сообществ. 
В связи с этим представляется важным рассмотрение недавно пришедшего из английского языка и быстро вошедшего в российскую языковую практику неологизма Brexit и установление наиболее продуктивных моделей образования новых слов в дискурсе СМИ на основе Brexit.

В соответствии с поставленной целью в данной научной статье решаются следующие задачи:

1) выявить специфику возникновения и функционирования концепта BREXIT;

2) установить теоретические подходы отечественных и зарубежных исследователей к словообразовательным моделям образования новых дериватов концептуализированного гнезда Brexit;

3) определить наиболее продуктивные словообразовательные модели в массмедийном дискурсе на основе анализа новой лексики концепта BREXIT.

В статье применяются следующие методы исследования: лингвистического наблюдения и описания, обобщения и контекстологического анализа.

Теоретической базой исследования послужили публикации зарубежных и отечественных авторов И. В. Арнольд, В. В. Елисеевой, В. И. Заботкиной, А. А. Воейковой, Е. М. Караваевой, Г. Лалик-Крстин, Н. Силашки, в которых рассматриваются проблемы образования новых лексических единиц по определенным словообразовательным моделям; работы, посвященные специфике функционирования неологизмов в массмедийном дискурсе (В. И. Заботкина, В. В. Катермина, Н. С. Соловьева, Е. М. Караваева).

Практическая значимость исследования: материалы исследования могут быть использованы в вузах гуманитарного направления при изучении и разработке таких дисциплин, как «Лексикология», «Практический курс иностранного языка», в переводческой и лексикографической практике.

\section{Специфика возникновения и функционирования концепта BREXIT}

В последнее время наблюдается возросший интерес исследователей к проблемам лингвокультурологии, изучающей отношения между языком и культурными концептами [21]. Особую важность для данной области науки представляет концепт - это «ментальное образование, которое представляет собой хранящиеся в памяти человека значимые осознаваемые типизируемые фрагменты опыта» [7, с. 8]. Самостоятельное функционирование новых лексических единиц в лингвокультурологии в качестве отдельных понятий может служить основанием для репрезентации определенного концепта.

Решение выйти из Европейского союза, принятое Великобританией в июне 2016 года, известное как Brexit, повлекло за собой серьезные политические, экономические и финансовые последствия во всем мире [15]. Лексическая единица Brexit имела и лингвистическое влияние, поскольку это событие привело к появлению большого количества производных и неологизмов в английском языке, таких как breferendum, brexiteer, Brexitsphere, regrexit или Brexitology и т.д., вербальное выражение которых стало частью языковой картины мира в понимании разных народов.

С лингвистической точки зрения слово Brexit, впервые упомянутое в британской прессе еще в 2012 году для выражения вероятного выхода Великобритании из Евросоюза, считается смоделированным после Grexit (Greece + exit / Греция + выход), «термина, который появился ранее в этом году в связи с возможностью выхода Греции из еврозоны». Термин “Grexit” был впервые сформулирован экономистом Эбрагимом Рахбари [17].

Следует отметить, что слово Brexit зарекомендовало себя как нарицательное слово в английском лексиконе. В 2014 и 2015 гг. было номинировано как Слово года в шорт-лист Oxford Dictionaries, а позже было внесено в их онлайн-словарь и определено там до фактического референдума как термин, обозначающий потенциальный или гипотетический выход Соединенного Королевства из ЕС, что может указывать на его относительно быструю конвенционализацию, лексикализацию и институционализацию в английском языке [15].

Язык статей, публикуемых английскими СМИ, остро реагирует на изменения, происходящие в социальной, экономической и политической жизни общества, и передает социальное настроение «пост-Брексита» образованием новых неологизмов. Из-за неуверенности и страха, отсутствия экономического и социального плана развития выражения с контрастирующим значением занимают господствующее положение; далее следуют выражения со значением иронии, а выражения с положительным значением занимают только третью позицию, оставляя позади выражения с пессимистическим значением, отражающие социальную незащищенность. Следовательно, экономические и политические перемены негативно сказываются на жизни общества, что, в свою очередь, может привести к изменению качества и структуры языка. Это также может существенно повлиять на процесс перевода вновь возникших неологизмов [20, p. 154].

\section{Обзор теоретических подходов ученых к словообразовательным моделям образования новых дериватов концептуализированного гнезда Brexit}

Проблемам образования новых лексических единиц по определенным словообразовательным моделям посвящены работы многих отечественных и зарубежных ученых: И. В. Арнольд, В. В. Елисеевой, В. И. Заботкиной, А. А. Воейковой, Е. М. Караваевой, Г. Лалик-Крстин, Н. Силашки. При этом проблема словообразования заключается в продуктивности модели и способа ее словообразования [6]. По утверждению В. И. Заботкиной, «наиболее продуктивными способами образования неологизмов в английском языке в 80-е годы XX столетия 
являлись словосложение (29,5\% от всего корпуса неологизмов), аффиксация (24\%) и конверсия (3\%), по сравнению с 60-70 годами, когда аффиксация преобладала над словосложением. Наиболее распространенными моделями словосложения считались “N + N = N” и “A + N = N”. Что же касается конверсии, то ее активность в 80-е годы снизилась и значительно уступала другим видам словообразования» [5]. По мнению А. А. Воейковой, результаты исследования данных за 2014 год показали, что словосложение сохраняет лидирующую позицию, на втором месте - сокращение (слияния, аббревиатуры, акронимы), а аффиксация и конверсия имеют наименьший удельный вес. Следует отметить сохранение продуктивности следующих моделей словосложения $(\mathrm{N}+\mathrm{N}=\mathrm{N}, \mathrm{A}+\mathrm{N}=\mathrm{N})$ и конверсии $(\mathrm{N} \rightarrow \mathrm{V})[3]$.

B настоящее время общепризнано, что в английском языке словосложение, аффиксация, сокращение, конверсия считаются наиболее продуктивными способами словообразования. Однако не все эти способы используются в одинаковой мере из-за их разного удельного веса в процессе образования новых слов. Наиболее активно используются словосложение и словопроизводство, поскольку значительное количество современных новообразований приходится их долю. По утверждению исследователей в области лингвистики, в последние 10-15 лет предпочтение отдается словосложению как одному из продуктивных способов словообразования. Остальные же модели словообразования - сокращение, лексикализация, словослияние, обратная деривация - не получили значительную популярность [4, с. 35].

Словосложение (англ. composition) представляет собой «продуктивный способ образования новых слов посредством объединения двух или более основ в единое целое» [2, с. 107].

Следует отметить, что зарубежные исследователи Г. Лалик-Кристин и Н. Силашки рассматривают концепт BREXIT в качестве модели для образования других неологизмов: Speхit и Itexit, относящихся к перспективе выхода Испании и Италии из ЕС. Как уже упоминалось ранее, сам неологизм Brexit был образован по модели Grexit. По мере приближения референдума в Великобритании и освещения в СМИ, создавая неопределенность, в считанные дни появились новые слова, обозначающие гипотетические сценарии в других странах ЕС: Аuхіt (Austria + exit), Bexit (Belgium + exit), Frexit (France + exit), Fixit (Finland + exit) и др. В некоторых случаях наблюдается появление нескольких слов для обозначения одной и той же страны: Germexit/Gerxit (Germany + exit), Pexit/Portexit/Portuxit/Portugexit (Portugal + exit) и др. [15]. Судя по тому, как был образован неологизм Вrехіt, можно увидеть поразительно большое количество сочетаний, наиболее продуктивных в настоящее время механизмов для создания новых слов, таких как "branalysis" (Brexit + analysis), "in-bretween” (in-between + Brexit), "breferendum" (Brexit + referendum), "brelax" (Brexit + relax), "Brexin” (Brexit + in), "brextrovert” (Brexit + extrovert) и др. Концептуализированное гнездо Brexit используется для образования новых слов - неологизмов, которые нетрудно интерпретировать. Тот факт, что brex-/bre-/br- хорошо узнаваемы в новых словах, является еще одним свидетельством того, что “Brexit” прочно укоренился и институализирован в лексиконе английского языка.

Вопросами особенности функционирования неологизмов в массмедийном дискурсе занимались многие современные исследователи (В. И. Заботкина [5], В. В. Катермина, Н. С. Соловьева [8], Е. М. Караваева [6] и другие). Следует отметить, что неологизмы в СМИ вызывают особый интерес у лингвистов, поскольку, являясь стратегической единицей коммуникации, они обладают экспрессивностью и привлекают внимание аудитории. Поэтому именно СМИ являются средством популяризации и распространения неологизмов.

\section{Наиболее продуктивные модели образования неологизмов концепта BREXIT}

На сегодняшний день в английском языке продуктивными способами образования слов, различающихся по результату использования, являются: сокращение (акроним, а также слово-слиток, результат - сокращение слова); словопроизводство (конверсия, аффиксация, реверсия, результат - создание производного слова); словосложение (результат - создание сложного слова).

В процессе анализа литературы было выявлено, что у разных исследователей имеются разные точки зрения на современные способы словообразования в английском языке. Прежде всего расхождения во мнениях обусловлены актуальностью того или иного способа и его продуктивностью или непродуктивностью в разные периоды времени. «Важно отметить, что определить продуктивность языковой модели можно исходя из критерия ее способности порождать открытие парадигмы, имеющие неограниченный состав элементов» [10, с. 19].

Следует отметить, что в современных условиях сокращение, в частности слияния и слова-акронимы, является распространенным способом образования возросшего числа неологизмов лексемы Brexit благодаря стремительному развитию интернет-технологий, тенденции к рационализации языка, к экономии языковых усилий [9].

В процессе слияния слов для образования неологизма во многих случаях усечению подвергаются оба слова, но есть также случаи, когда усечению подвергается только один компонент (Таблица 1). Так, например, неологизм Brexit был образован путем слияния усеченного слова Britain до первых двух букв и слова ехіt. Таким же образом было образовано большинство неологизмов, обозначающих эмоции и процессы, связанные с исходом референдума.

Через неделю после всенародного голосования за выход из ЕС большие слои общества задают серьезные вопросы о будущем Великобритании и своем месте в ней. “The question we should be asking ourselves is how our Brexistential crisis can become a source of energy for creating new forms of social, economic and cultural life" [22]. I Вопрос, который мы должны задать себе, заключается в том, как наш кризис, предопределенный «Брекситом», может стать источником энергии для создания новых форм социальной, экономической и культурной жизни. 
Таблица 1. Неологизмы концептуализированной группы Brexit, образованные путем слияния

\begin{tabular}{|c|c|c|}
\hline \multicolumn{2}{|c|}{ Слияние с усечением одного компонента } & \multirow{2}{*}{$\begin{array}{c}\text { Перевод (здесь и далее перевод автора статьи. - Д. В.) } \\
\text { одобрение выхода Великобритании из ЕС }\end{array}$} \\
\hline bracceptance & Brexit + acceptance & \\
\hline braccident & Brexit + accident & «Брексит»-катастрофа \\
\hline branalysis & Brexit + analysis & анализ «Брексита» \\
\hline branger & Brexit + anger & возмущение, связанное с выходом Великобритании из ЕС \\
\hline branxiety & Brexit + anxiety & страх, связанный с выходом Великобритании из ЕС \\
\hline brexample & Brexit + example & $\begin{array}{l}\text { пример, связанный с выходом Великобритании из ЕС; попытка сравнить тяже- } \\
\text { лые испытания «Брексита» с другими знаменательными моментами истории }\end{array}$ \\
\hline brexamination & Brexit + examination & изучение «Брексита» \\
\hline brexcellent & Brexit + excellent & $\begin{array}{l}\text { когда все основные политические партии в Великобритании соглашаются } \\
\text { друг с другом и страна объединяется в попытке осуществить «Брексит» } \\
\text { и стать доминирующей силой во всем мире }\end{array}$ \\
\hline brexecuted & Brexit + executed & $\begin{array}{l}\text { «Брексит» подписан; соглашение о выходе Великобритании из ЕС подписано; } \\
\text { завершение «Брексита» сигнализирует о выходе Великобритании из ЕС }\end{array}$ \\
\hline brexemption & Brexit + exemption & $\begin{array}{l}\text { послабления, освобождение (напр., от уплаты налогов), связанные с выходом } \\
\text { Великобритании из ЕС }\end{array}$ \\
\hline brexercise & Brexit + exercise & $\begin{array}{l}\begin{array}{l}\text { использовать право проповедовать свою точку зрения на «Брексит» } \\
\text { как правильную }\end{array} \\
\end{array}$ \\
\hline brexert & Brexit + exert & приводить в действие «Брексит» \\
\hline brexhausted & Brexit + exhausted & быть утомленным темой «Брексита» \\
\hline brexhibition & Brexit + exhibition & продемонстрировать идею о «Брексите» \\
\hline brexistence & Brexit + existence & образ жизни после «Брексита» \\
\hline brexistential & Brexit + existential & предопределенный «Брекситом» \\
\hline brexodus & Brexit + exodus & массовый отъезд граждан ЕС из Великобритании в ожидании «Брексита» \\
\hline brexpert & Brexit + expert & $\begin{array}{l}\text { эксперт, помогающий общественности разобраться в постоянно меняющей- } \\
\text { ся теме выхода Великобритании из ЕС }\end{array}$ \\
\hline brexplosion & Brexit + explosion & вспышка гнева, вызванная «Брекситом» \\
\hline brexternal & Brexit + external & не имеющий отношения к «Брекситу» \\
\hline brextra & Brexit + extra & прибыль от «Брексита» \\
\hline brextraneous & Brexit + extraneous & совершенно не связанный с «Брекситом» \\
\hline brextraordinary & Brexit + extraordinary & все, что связано с «Брекситом», воспринимается как экстраординарное \\
\hline brextremist & Brexit + extremist & $\begin{array}{l}\text { тот, кто выступает за полный и немедленный выход Великобритании из ЕС } \\
\text { и всех связанных с ним организаций, независимо от последствий }\end{array}$ \\
\hline \multicolumn{3}{|c|}{ Слияние с усечением двух компонентов } \\
\hline brant & Brexit + rant & $\begin{array}{l}\text { долго говорить на тему «Брексита», независимо от того, интересует ли эта } \\
\text { тема кого-либо или нет }\end{array}$ \\
\hline brargaining & Brexit + bargaining & $\begin{array}{l}\text { соглашение, связанное с процессом «Брексита», между двумя людьми или } \\
\text { группами, в котором каждый обещает сделать что-то в обмен на что-то другое }\end{array}$ \\
\hline brecession & Brexit + recession & $\begin{array}{l}\text { брецессия; кризисные явления на макроэкономическом уровне, характерные } \\
\text { для экономики Великобритании после прекращения ее членства в ЕС }\end{array}$ \\
\hline breconsideration & $\begin{array}{l}\text { Brexit }+ \\
\text { reconsideration }\end{array}$ & $\begin{array}{l}\text { процесс обдумывания решения или мнения о «Брексите» и принятия решения } \\
\text { о его изменении }\end{array}$ \\
\hline bredictable & Brexit + predictable & $\begin{array}{l}\text { ситуация с «Брекситом», т.е. выходом Великобритании из Евросоюза, несо- } \\
\text { мненно относится к предсказуемым событиям }\end{array}$ \\
\hline bre-do & Brexit + redo & $\begin{array}{l}\text { повторить голосование по референдуму, в результате которого Великобритания } \\
\text { приняла решение выйти из Европейского союза }\end{array}$ \\
\hline breferendum & Brexit + referendum & референдум о выходе Великобритании из ЕС \\
\hline breflection & Brexit + reflection & брефлексия; обдумывание процесса выхода Великобритании из Евросоюза \\
\hline bregret & Brexit + regret & сожалеть о «Брексите» \\
\hline brelax & Brexit + relax & $\begin{array}{l}\text { смягчение правил (напр., для небольших банков и строительных обществ) } \\
\text { после завершения перехода к Brexit }\end{array}$ \\
\hline bremainder & Brexit + remainder & человек, который считает, что Великобритания должна оставаться в ЕС \\
\hline bremorse & Brexit + remorse & чувство сожаления после «Брексита» \\
\hline brenial & Brexit + denial & отказ от «Брексита» \\
\hline brepeat & Brexit + repeat & повторение событий «Брексита» \\
\hline brepression & Brexit + depression & депрессия из-за «Брексита» \\
\hline bresults & Brexit + results & результаты «Брексита» \\
\hline brethink & Brexit + rethink & пересмотр решения или мнения о «Брексите» \\
\hline Brexicon & Brexit + lexicon & лексика «Брексита» \\
\hline brevastation & Brexit + devastation & опустошение, нанесенное «Брекситом» \\
\hline breverse & Brexit + reverse & отмена «Брексита», например, в результате второго референдума \\
\hline brollocks & Brexit + bollocks & $\begin{array}{l}\text { пугающие истории после «Брексита», придуманные лжецами, которые } \\
\text { не могут принять результаты правительственного референдума }\end{array}$ \\
\hline regrexit & regret + Brexit & $\begin{array}{l}\text { сожалеть о том, что проголосовал «за» на референдуме о выходе Великобри- } \\
\text { тании из ЕС }\end{array}$ \\
\hline
\end{tabular}


Автор статьи другой англоязычной газеты “Тhe Times” вводит новый термин “Brecession”, предсказывая экономический спад, начертанный «Брекситом»: “May I be the first to coin the term Brecession? This is the name of a domestic downturn that does not reflect world trends but appears to be home grown. I shall claim my prize when Brexit leads to Brecession and ends in Bremorse, leading to a Breconsideration of the whole darn thing, and the final victory of Bremain. A period of calm Breflection is now called for" [18]. / Могу я первым ввести термин «Брецессия»? Это название экономического спада внутри страны, который не отражает мировых тенденций, но, похоже, является доморощенным. Я заберу свой приз, когда «Брексит» приведет к «Брецессии» и закончится чувством сожаления после «Брексита», что приведет к обдумыванию решения о «Брексите» и принятию решения об изменении всей этой чертовщины и окончательной победе решения о сохранении членства Великобритании в ЕС. Настал период спокойного обдумывания процесса выхода Великобритании из Евросоюза.

Слияния, созданные с исходными словами, отличными от Brexit, включают Brentry, Breturn - неологизмы, созданные ретроспективно по аналогии с Brexit: brentry (Britain/British + entry), breturn (Britain/British +return), bremain (Britain/British + remain).

Так, например, заголовок статьи в английской газете “The Times” “Forget 'Breturn': the EU won't have us back” [19] («Забудьте о “возвращении членства Великобритании в ЕС”: ЕС нас не вернет») передает настроение британского электората спустя два года после референдума и сомнение в воссоединении с ЕС в будущем, поскольку «после всей суматохи и раздражения, которые мы вызываем, возможно ли, что ЕС захочет нас?».

В английском языке образование неологизмов при помощи аффиксов (префиксов и суффиксов) является наиболее традиционным. Слово Brexit, а также неологизмы, образованные с его помощью - bregret и bremain, до сих пор используются в качестве основы для образования существительных путем добавления одного из самых продуктивных суффиксов -er: brexit-brexiteer, brexiter (сторонник выхода из ЕС, евроскептик); bregret - bregretter (человек, сожалеющий о выходе Великобритании из ЕС); bremain - bremainder (сторонник сохранения британского членства в ЕС). Пример использования неологизма Brexiters: “We stand this weekend on the brink of a no-deal crash-out from the European Union: the very outcome that all but the most extreme Brexiters once agreed would be a catastrophe for this country, an outcome our leaders insisted would never happen" [13]. / В эти выходные мы стоим на грани полного выхода из Европейского союза: результат, который станет катастрофой для страны, по общему мнению всех, кроме самых бескомпромиссных сторонников «Брексита», результат, к которому мы не должны были прийти, по заверению наших руководителей.

Среди префиксов предпочтение отдается префиксу post-, что объясняется образованием с его помощью прилагательного post-Brexit. К примеру: post-Brexit relationship (отношения после «Брексита»); post-Brexit strategy («nост-Брекситовская» стратегия); post-Brexit Britain (Британия после «Брексита»). В статье англоязычной газеты “Financial Times” обсуждается актуальность реформ экономической политики Великобритании и стратегии развития страны после ее выхода из Евросоюза: “It is in economic policy where the requirement for a post-Brexit strategy is most urgent” [12]. / Именно в экономической политике требование «пост-Брекситовской» стратегии является наиболее актуальным.

Помимо аффиксации, в образовании неологизмов концептуализированной группы Brexit в английском языке используется также конверсия, «способ словообразования, который предполагает образование от одной части - другой, без внесения каких-либо изменений во внешнюю форму слова» [11, с. 120]. Сегодня среди различных типов конверсий наибольшей популярностью пользуется вербализация существительных. Исходя из информации Таблицы 1, мы видим, что три существительных были преобразованы в глаголы: bregret (сожалеть о «Брексите»), brexit (прекратить членство Великобритании в ЕС) и regreхіt (сожалеть о том, что проголосовал «за» на референдуме о выходе Великобритании из EC). Глагол brexit использовался в сокращенной форме brex, например, в “Don't go brexin my heart” [15]. Анализ материала исследования выявил, что способ образования неологизмов путем конверсии в настоящее время очень редко применяется и уступает всем остальным способам словообразования.

Исследование практического материала позволило выделить еще один распространенный способ образования неологизмов концептуализированной группы Brexit - это словосложение. К примеру, Brexitography, Brexitometer, Brexitology, Brexitophobia. Пример использования: "Residents overwhelmingly want to stop Brexit, as an Islington 'Brexitometer' has found. The 'Brexitometer' - a sticker survey - was erected in Upper Street on Monday as Liberal Democrats launched their European election campaign” [24]. / Подавляющее большинство жителей хотят остановить «Брексит», как показал ислингтонский «Брекситометр». «Брекситометр»- стикер-опрос - был установлен на Аппер-стрит в понедельник, когда либерал-демократы начали свою европейскую избирательную кампанию.

\section{Заключение}

Итак, данное исследование позволяет сделать следующие выводы. Решение о прекращении членства Великобритании в Евросоюзе в июне 2016 года, известное как Brexit, послужило причиной появления большого количества производных или неологизмов в английском языке. Многие отечественные и зарубежные лингвисты занимаются изучением неологизмов концептуализированного гнезда Brexit, в частности их словообразовательными моделями, которые важны при переводе на другие языки. Рассмотренные в нашем исследовании 
способы образования неологизмов концептуализированного гнезда Brexit, такие как словосложение, аффиксация и сокращение, являются продуктивными в массмедийном дискурсе, что означает их способность формировать новые слова. Как известно, образование новых лексем происходит в соответствии с законами языка, с использованием продуктивных моделей словообразования.

Перспективы дальнейшего исследования проблемы мы видим в более детальном изучении неологизмов слова Brexit как части языковой картины мира в понимании носителей современного английского языка, поскольку число дериватов, образованных главным образом при помощи слияния основ, как и число устойчивых сочетаний с этой единицей, постоянно растет.

\section{Список источников}

1. Арнольд И. В. Лексикология современного английского языка: учеб. пособие. М.: ФЛИНТА; Наука, 2012. 376 c.

2. Арнольд И. В. Стилистика современного английского языка. М.: Просвещение, 1990. 300 с.

3. Воейкова А. А. Особенности словообразования новой лексики в английском языке (на примере неологизмов, зафиксированных на интернет-сайте www.wordspy.com) [Электронный ресурc]. URL: https://appliedresearch.ru/ru/article/view?id=6492 (дата обращения: 18.01.2021).

4. Елисеева В. В. Лексикология английского языка. СПб.: СПбгУ, 2003. 80 с.

5. Заботкина В. И. Новая лексика современного английского языка [Электронный ресурс]: уч. пособие для ин-тов и фак-тов ин. яз. М.: Высшая школа, 1989. URL: https://classes.ru/grammar/138.Zabotkina/ (дата обращения: 30.03.2021).

6. Караваева Е. М. Продуктивные модели словообразования неологизмов концептуализированной группы Brexit в современном английском языке (на материале британской прессы и социальных сетей) // Культура и цивилизация. 2017. Т. 7. № 6А. С. 376-381.

7. Карасик В. И. О категориях лингвокультурологии // Языковая личность: проблемы коммуникативной деятельности: сборник научных трудов. Волгоград: Перемена, 2001. С. 3-16.

8. Катермина В. В., Соловьева Н. С. Аксиология неологизма Brexit в англоязычном массмедийном дискурсе [Электронный ресурс]. URL: https://cyberleninka.ru/article/n/aksiologiya-neologizma-brexit-v-angloyazychnommassmediynom-diskurse (дата обращения: 20.01.2021).

9. Мартине А. Принцип экономии в фонетических изменениях: проблемы диахронической фонологии. М.: Изд-во иностр. лит-ры, 1960. 301 с.

10. Мельцер Е. М. К вопросу о процессах словообразования современного английского языка (на материале неологизмов последних двух десятилетий) // Иностранный язык в школе. 1957. № 4. С. 17-27.

11. Мешков О. Д. Словообразование современного английского языка. М.: Наука, 1976. 245 с.

12. Bold reform for a post-Brexit Britain [Электронный ресурc]. URL: https://www.ft.com/content/1cb4b90c-a1a34c0f-9476-3f0a4e394921 (дата обращения: 26.01.2021).

13. Freedland J. Britain faces a no-deal crash-out: Even ultra-Brexiters said this would be a disaster [Электронный pecypc]. URL: https://www.theguardian.com/commentisfree/2020/dec/11/britain-no-deal-crash-out-ultra-brexitersdisaster (дата обращения: 10.01.2021).

14. Hutton R. A new place of exile [Электронный ресурс]. URL: https://richardhutton.wordpress.com/ (дата обращения: 29.01.2021).

15. Lalić-Krstin G., Silaški N. From Brexit to Bregret: An account of some Brexit-induced neologisms in English // English Today. 2018. Vol. 34. № 2. P. 3-8. DOI: 10.1017/S0266078417000530.

16. Macmillan dictionary [Электронный ресурc]. URL: https:/www.macmillandictionary.com/ (дата обращения: 13.02.2021).

17. Maxwell K. BuzzWord: Brexit [Электронный ресурc]. URL: https://www.macmillandictionary.com/buzzword/ entries/brexit.html (дата обращения: 18.01.2021).

18. Parris M. I predict Brecession... and then Bremorse // The Times. 2016. July 06.

19. Powis D. Forget 'Breturn': The EU won't have us back // The Sunday Times. 2018. Sept. 30.

20. Ruga E., Hioară N. Modern Socio-economic Language and Communication (Brexit Topic) // Studia Linguistica. 2017. Vol. 11. P. 154-164.

21. Sharifian F. Cultural Conceptualisations and Language: Theoretical Framework and Applications. Amsterdam Philadelphia: John Benjamins, 2011. 238 p.

22. Spicer A. The UK is in Brexistential crisis. Is there a way forward? [Электронный pecypc]. URL: https://www.theguardian. com/commentisfree/2016/jul/01/uk-brexit-brexistential-vote-leave-eu-britain (дата обращения: 23.01.2021).

23. Urban dictionary [Электронный ресурc]. URL: https://www.urbandictionary.com/ (дата обращения: 13.02.2021).

24. Wakeling N. Polls are chance to send a message that we're committed to the EU [Электронный ресурс]. URL: http://camdennewjournal.com/article/polls-are-chance-to-send-a-message-that-were-committed-to-the-eu? sp=0\&sq=election\%2520losses (дата обращения: 29.01.2021). 


\section{Информация об авторах | Author information}

RU Васьбиева Динара Гиниятулловна ${ }^{1}$, к. экон. н., доц.

${ }^{1}$ Финансовый университет при Правительстве Российской Федерации, г. Москва

EN Vasbieva Dinara Giniyatullovna ${ }^{1}, \mathrm{PhD}$

${ }^{1}$ Financial University under the Government of the Russian Federation, Moscow

${ }^{1}$ dinara-va@list.ru

\section{Информация о статье | About this article}

Дата поступления рукописи (received): 29.01.2021; опубликовано (published): 30.04.2021.

Ключевые слова (keywords): неологизм; концептуализированное гнездо Brexit; продуктивные модели словообразования; массмедийный дискурс; neologism; conceptualised group Brexit; productive word-formation models; mass media discourse. 